\title{
MEASURING BUSINESS PROCESS EFFICIENCY USING AHP
}

\author{
Frances X. Frei \\ Simon School of Business \\ University of Rochester \\ Rochester, NY 14627 U.S.A. \\ frei@mail.ssb.rochester.edu \\ Patrick T. Harker \\ The Wharton School \\ University of Pennsylvania \\ Philadelphia, PA 19104-6366 U.S.A. \\ harker@eniac.seas.upenn.edu
}

\begin{abstract}
When one undertakes benchmarking of organizational performance, it is quite typical to collect performance data on a set of business processes from a variety of organizations. While one can compare efficiency on a process by process level, how can one compare the overall efficiency of one organization versus another using this process-level data? This paper presents a methodology that combines toumament ranking and AHP approaches to create a ranking scheme that deals explicitly with missing data and ties in the tournament scheme. Using data from the Wharton/Sloan study on financial services, the methodology will be illustrated by analyzing the efficiency of 11 service delivery processes in over 130 North American retail banks.
\end{abstract}

\section{Introduction}

Benchmarking studies in industry typically involve the collection of a vast quantity of statistical, anecdotal, and qualitative information concerning the relative performance of various business processes within and between organizations. Thus, such benchmarking is at the heart of the modern reengineering phenomena that is sweeping through organizations throughout the world (Hammer and Champy 1993; Davenport and Short 1990).

More than just an interesting tool for industry, the ability to compare the relative merits of various business process designs is crucial in understanding the drivers of competitiveness and performance in organizations. The design of a business process is neither an input or output as it is neither created nor consumed as other inputs and outputs, but rather provide the structure for the creation and consumption of the existing inputs and outputs. The process, according to Morroni (1992), actually defines how capital and labor interact in order to produce outputs. For example, Morroni (1992) provides an illustrative example where there are ten ditch diggers with 10 shovels. If an eleventh shovel is added, the process of ditch digging must be changed. That is, the one-person, one-shovel process will not be benefited by an additional shovel. The point here is that a process typically defines the relationship between capital and labor and thus, they are not immediately interchangeable. Thus, the process design defines the production technology for the organization.

Given that process designs are not the same as inputs like labor, how can processes be analyzed for their relative efficiency? For analyzing the relative efficiency of a single process, Frei and Harker (1996) present an extension of Data Envelopment Analysis (DEA) to incorporate process design characteristics. However, organizations are composed of multiple business processes. How are we to compare one organization to another when we are given business process-level data? This question is the focus of the current paper.

${ }^{1}$ This research was funded by a grant from the Alfred P. Sloan Foundation to the Wharton Financial Institutions Center. 
The remainder of this paper is structured as follows. The next section will review the Frei and Harker (1996) method for analyzing the efficiency of a single process and will be followed by the description of our proposed method of aggregating these single process metrics to create organizational efficiency scores. The paper will then conclude with the description of an application of this method to analyze organizational efficiency in the U.S. banking industry.

\section{Analyzing Single Process Efficiency}

Frei and Harker (1996) describe an extension of DEA to analyze the relative efficiency of a given business process across multiple organizations. Creating a process map is the standard first step in the evaluation of processes (Shostack, 1987; Kingman-Brundage, 1992). However, even after a careful study of process maps has occurred, it is still difficult to determine how efficient a single process is or, from a group of processes, which is "better". There is no existing methodology that helps us compare processes. The technique that is described by Frei and Harker (1996) builds on existing frontier estimation methods to provide a way to evaluate processes with multiple inputs and outputs, at least some of which have non-market values. The first step is to determine the relative efficiency of a given process, which other firms might be used for benchmarking a given process, and the managerial implications of the choices involved.

Frei and Harker (1995) introduced a method for determining relative efficiency scores by projecting to the closest point on the efficient frontier. They also demonstrated the importance of listing efficiency scores for projections onto the entire frontier as well as to the observable portion of the frontier. This section adds the effect of process technology to the previously described methodology. That is, the performance of a given process has already been assessed over multiple inputs and outputs with capital and labor presumably as inputs, and some notion of performance scores as outputs. The question addressed by Frei and Harker (1996) is what role the process has in this evaluation.

The work of Brockett and Golany (1994) introduces the concept, in the context of Data Envelopment Analysis (DEA), of organizing decision making units (DMUs) into subgroups in order to determine if one subgroup outperforms another. This logic is easily transferred to processes, where the thought is that although all processes require the same categories of inputs to produce similar categories of outputs; there $\because$ are vastly different ways of organizing the way in which this occurs. Brockett and Golany determine the efficient frontier for each subgroup in order to determine under which input and output scenarios each subgroup is dominant. The problem with their work is that although it is easy to visually understand which process design group is dominant in two dimensions, they provide no means of deteimining this in higher' dimensions. Thus, their idea of comparing frontiers is useful' in two dimensions but is not-yet' possible in higher dimensions. In our work, we take this notion of Brockett and Golany's-and implement it differently. That is, we determine the overall frontier and then the frontier for each process design group, but then determine if the DMUs on one frontier have statistically different overall efficiency ratings from another. In addition, on an individual DMU basis, we look at the efficiency within their subgroup as well as the efficiency overall in order to deternine which portion of the overall inefficiency is due to poor execution and which is due to belonging to the wrong subgroup.

In particular, this subsection addresses the process by which an organization or DMU converts its inputs to outputs. That is, is the process or its design an additional input or output like labor and capital, or does it. exhibit other characteristics? As stated in the Introduction, it is difficult to think of design characteristics as either inputs or outputs as they are neither created nor consumed as other inputs and outputs, but rather . provide the structure for the creation and consumption of the existing inputs and outputs. Thus, the process design defines the production technology for the organization.

Given that process designs are not the same as inputs like labor, how can the method described in Frei and Harker (1995) be extended to account for process designs and to analyze their relative efficiency? First, it is important to recognize that when determining the empirical production function or efficient frontier that we are defining $F(x, y, z)$ where $x$ is the set of inputs, $y$ [is the set of outputs, and $z$ is the set of other characteristics that influence the production but which are not captured in the model. It is the subset of $z$ represented by process design characteristics that we are focusing on here. That is, we recognize that there are always model externalities contributing to production and we are attempting to capture the effect of 
design characteristics. Obviously these design characteristics are neither consumed nor produced but yet they may still play an important role in production. It is to this end that we are taking the additional step to treat the designs as defining alternative production functions. That is, in addition to looking at the empirical production function, or efficient frontier, of the entire data set, we find it useful to look at the set of empirical production functions represented by each of a class of design groups. This is essential as it allows us to determine how well a DMU is performing relative to their own design group as well as how well they are performing overall.

In order to determine the set of efficient frontiers, one must first categorize processes with respect to their key design elements, and then determine the performance of a DMU with respect to the overall efficient frontier (consisting of a combination of process designs) as well as within their own process design-group. If suitable process-design groups can be determined, either by inspection or by cluster analysis, then the overall inefficiency of a bank can be split into its attributable components of poor performance and inferior process design. These process-design groups can be determined after analyzing each of the processes, listing their design attributes, and clustering on these attributes.

After the process-design groups have been determined, the shortest-distance algorithm described in Frei and Harker (1995) is run independently on each group in order to determine relative performance within the group, and, more importantly, to determine when it is beneficial to attempt to improve performance within the same process, and when it is beneficial to change processes. Figures 1-3 illustrate an example with two process design groups, where the boxes and circles represent two distinct process designs. From Figure 1, it is clear that the overall frontier contains D1 though D4 with all other DMUs inefficient. Figures 2 and 3 , however, show how the process design groups create their own frontier. That is, Figure 2 depicts process-design Group I's fiontier and Figure 3 depicts process-design Group II's frontier. Each inefficient DMU now has two projections, one to the overall frontier and one to its design group's frontier. The task is to determine all three frontiers along with all of the associated distance measurements, projections, and reference sets.

There are three categories that a DMU might fall in when the analysis is performed. The first is that the DMU is efficient overall and is thus efficient in any design group. The second category is that the DMU is inefficient overall but efficient in its design group. In order to look for improvement there are two possibilities. One is for the DMU to stay within the same design group and to look to move the frontier. $\because$ The second possibility is to look for improvement by changing design groups. The third category is that the DMU is inefficient overall and in its design group. In this case, it is not clear what the reference set should be. If the shortest projection to the design group frontier lands on the overall frontier then it is likely that the inefficiency is due to poor performance rather than the wrong process design. However, if the shortest projection to the design group frontier does not land on the overall frontier, then there can be a performance and design group choice component of the inefficiency.

The methodology for evaluating a process can be summarized as follows:

Step 1. Determine the efficiency scores, reference set, and frontier projection for the entire data set using the methodology developed in Frei and Harker (1995).

Step 2. Separate the data into process dèsign groups using cluster analysis on specific process characteristics.

Step 3. Determine the efficiency scores, reference set, and frontier projection for each process design group separately, as described-in-Step 1.

Step 4. Isolate the portion of overall inefficiency that is due to poor performance and the portion that is due to the wrong process design. The overall and design group efficiency scores have been determined in Steps 1 and 3 respectively. If the DMU is inefficient in both then the portion of the overall inefficiency that is due to poor execution is

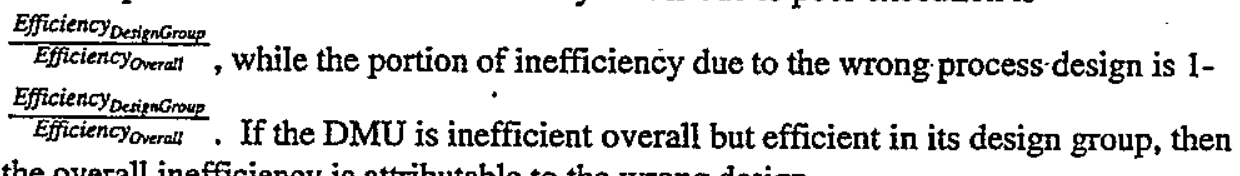
the overall inefficiency is attributable to the wrong design.

Step 5. Determine the specific managerial recommendations for improvement both within a design group as well as overall. 


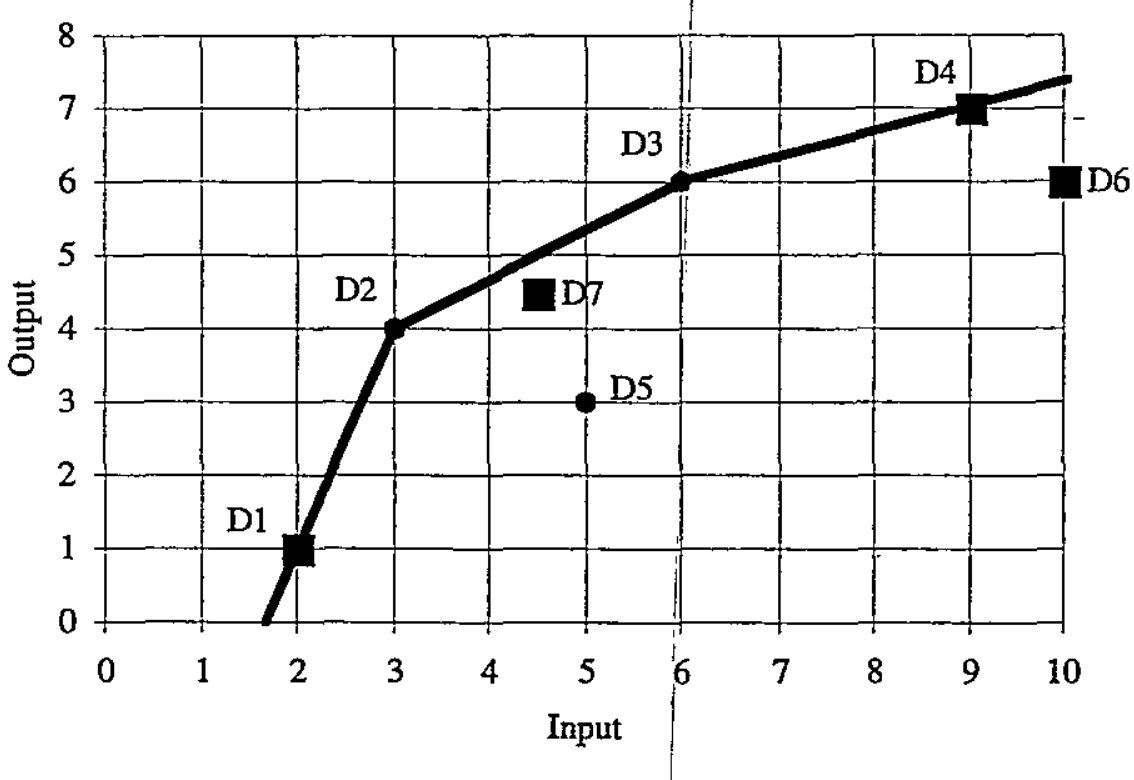

Figure 1. Overall Frontier for Two Process Design Groups

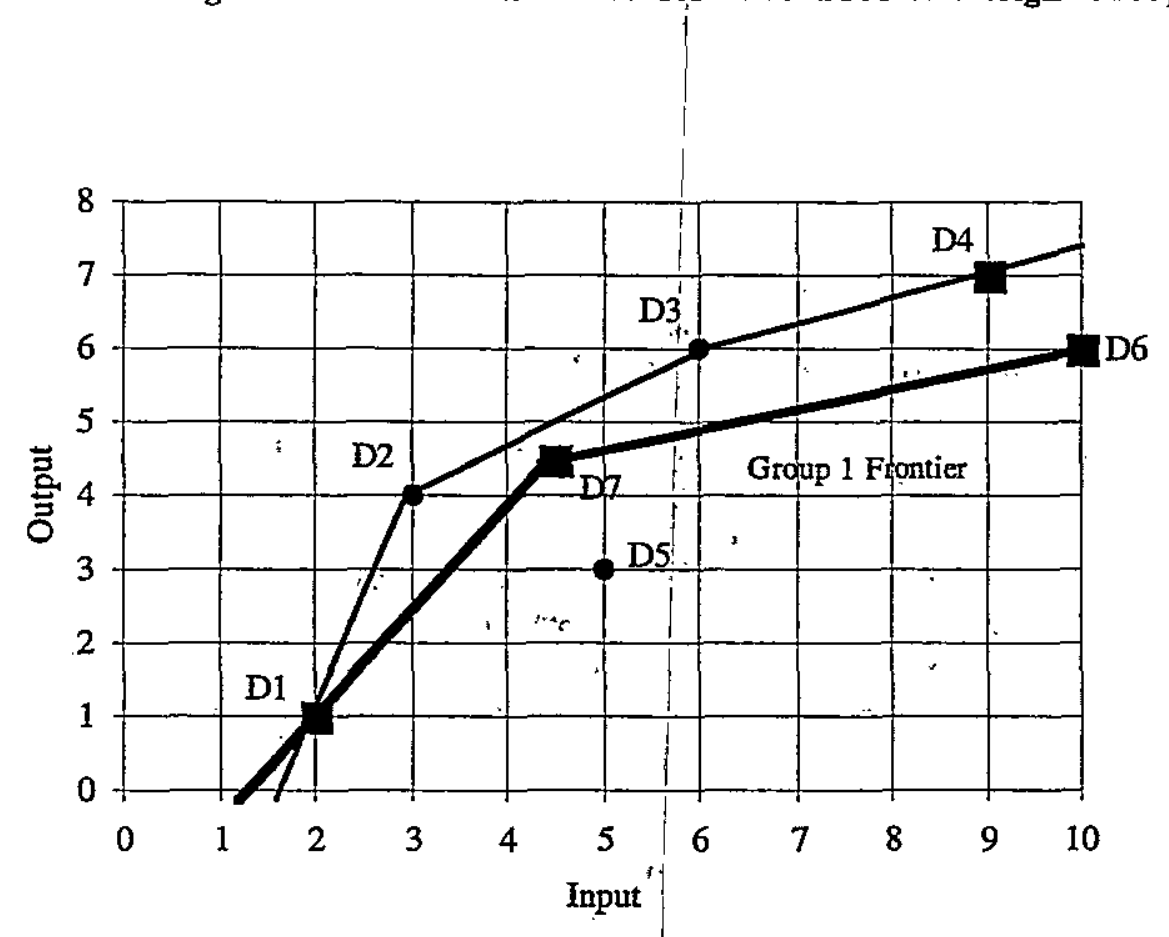

Figure 2. Process-Design Group I Frontier 


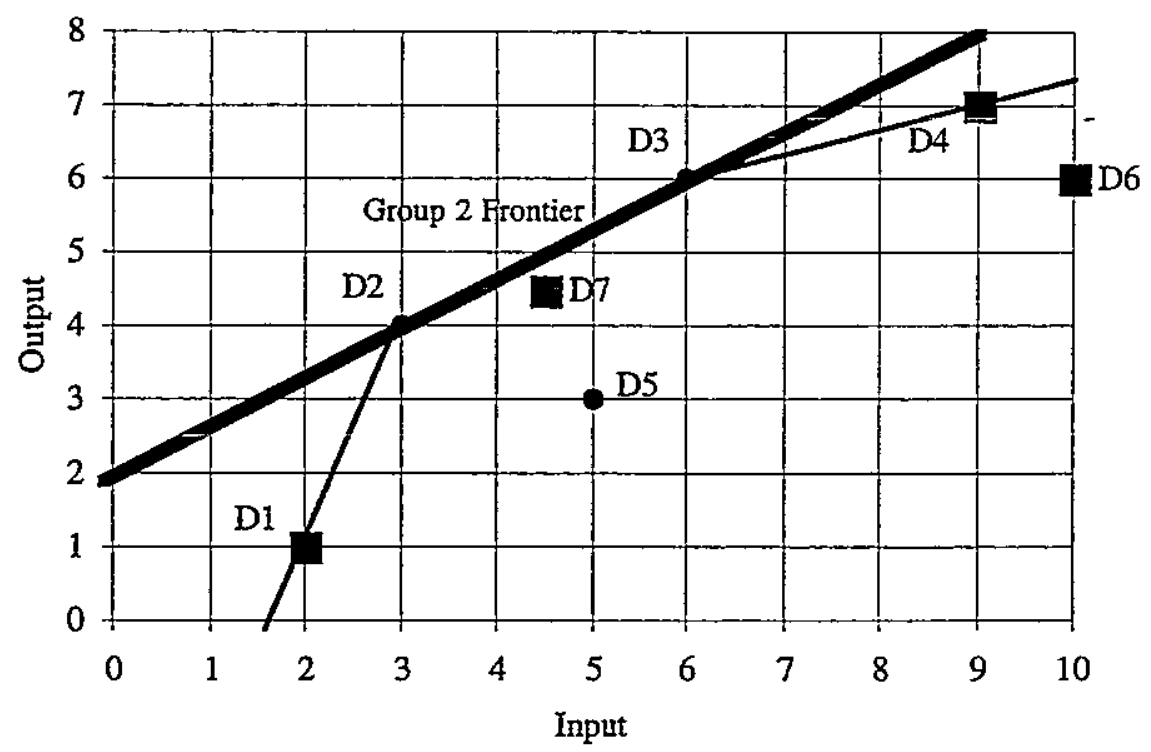

Figure 3. Process-Design Group II Frontier

\section{Analyzing Organizational Efficiency}

The previous section outlined an approach for analyzing the efficiency of business processes on a processby-process basis. However, organizations are a collection of such processes. How can these be aggregated to form an index of efficiency for the organization as a whole? This question is addressed herein.

A standard approach for aggregating data at an institutional or 'team' level is to conduct institutional comparisons is a tournament ranking scheme (David 1963). The first step in using a tournament ranking scheme is to develop a matrix of 'wins'; i.e. a matrix $W=\left(w_{i j}\right)$ where each entry, $w_{i j}$, represents the number of times that Participant $i$ beat Participant $j$. That is, if there are 10 participants there will be a $10 \times 10$ matrix such that each entry in the matrix $W=\left(w_{i j}\right)$ represents the number of times Participant $i$ performed better than Participant $\mathrm{j}$. In the case where two participants have never competed against each other, the entries are left blank and treated as "missing data." Using the correctiondeveloped by Harker (1987) for missing data, we simply add 1 to the diagonal for each bank that has missing data, and place a zero in the missing data locations.

In the case where Participant $i$ outperforms Participant $j$ for all of their common processes, zero would be

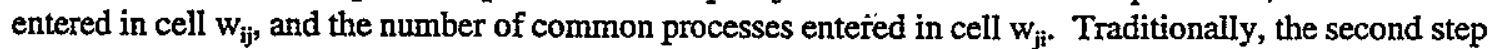
in tournament ranking analysis is to develop a matrix of wins-to-losses where each entry is replaced with

$\frac{w_{y j}}{w_{j l}}$. However, when we consider the case where one participant wins all of the matches against another participant, we see that this would yield an undefined value as one entry in the wins-to-losses matrix. In order to adapt our situation to the existing literature, we are guided by Saaty's (1986) principal that the scaling of a matrix should be 'bounded'. That is, in no case should one organization be considered infinitely better than another, but rather the discrepancy is bounded by some limit. This is further evidenced in the work of Harker and Vargas (1987) on the Analytical Hierarchy Process. Thus, rather than having each matrix entry as the number of wins divided by the number of losses or $\frac{w_{i j}}{w_{j i}}$ (where we would have potentially undefined entries), we have each entry represented by $e^{\operatorname{In}(\alpha) \frac{\omega_{j}-\omega_{j}}{w_{i j}+w_{j i}}}$, where $\alpha$ represents the bound of how much better one organization is than another. We use the number proposed by Saaty (1986) for this bound (i.e., $\alpha=9$ ). This allows for an entry of 1 when two organizations have the same numbers of wins and losses and ranges from $1 / \alpha$ to $\alpha$ for the range of possible performance scores when there are uneven 
wins and losses. Thus, if one participant wins all of the matches, that participant will have an entry of 9 in the wins-to-losses matrix, and the losing participant will have an entry of $1 / 9$.

Formally, the algorithm we use for the tournament ranking scheme is as follows: -

Step 1. Determine the rank of each institution for each process using the process described in Frei and Harker (1996).

Step 2. Determine a matrix of "wins" and "losses" for each process by having entry $w_{i j}=$ the number of processes for which institution $i$ outranks institution $j$. Enter a 1 for each diagonal entry.

Step 3. For each instance in which there are no competitions in common between two participants, add 1 to the diagonal for each participant, and replace the empty cell with a zero.

Step 4. Scale the win-loss matrix with $e^{\ln (\alpha)^{\frac{w_{j}-w_{j i}}{w_{j i}+\omega_{j i}}}}$ to ensure that one organization is not considered infinitely better than another. Do not perform the scaling for "missing data" cells but rather keep their value as zêro.

Step 5. Determine the eigenvector of the scaled win-loss matrix. This eigenvector contains the relative performance of each institution for the set of processes.

In order to illustrate this algorithm we describe a small example. Assume that there are three competitors that have competed against each other anywhere from zero to ten times. The matrix shown in Table 1 represents the number of times that each competitor beat its respective challengers (Step 2). For example, A competes against $B$ eighteen times. A wins ten of its matches and $B$ wins eight of its matches.

Table 1. Sample Matrix of Wins

\begin{tabular}{llc|}
\hline & A & B \\
\hline A & 0 & 10 \\
B & 8 & 0 \\
C & 0 & 10 \\
\hline
\end{tabular}

C

9

0

0

The next step is to determine which participants did not compete against each other (Step 3). In this example, all three participants competed against each other. If there were any that did not, we would simply add one to the diagonal for each and replace the empty cells with zero. Next we scale each entry according to the formula $e^{\ln (\alpha) \frac{w_{j / j}-m_{j p}}{w_{j}+w_{j}}}$ in order to determine the scaled matrix of wins-to-losses (Step 4). The scaled results are recorded in Table 2.

Table 2. Scaled Matrix of Wins to Losses

\begin{tabular}{lcc:|c}
\hline & $\mathrm{A}$ & $\mathrm{B}$ & $\mathrm{C}$ \\
\hline $\mathrm{A}$ & 1 & 1.277 & 9 \\
$\mathrm{~B}$ & 0.783 & 1 & 0.111 \\
$\mathrm{C}$ & 0.111 & 9 & 1 \\
\hline
\end{tabular}

Finally, we determine the eigenvector of the matrix using the scaled data and then determine the subsequent ranking as shown in Table 3 . As we can see from Table 3, the order of aggregate performance ranking of these three participants is A, C, B. 
Table 3. Eigenvalues and Rankings

\begin{tabular}{lcc}
\hline & Eigenvector & Rank \\
\hline A & 0.8998 & 1 \\
B & 0.1767 & 3 \\
C & 0.3988 & 2 \\
\hline
\end{tabular}

The methodology we have just described allows us to generate, for each institution, a composite process performance score by comparing processes. This composite score allows us to determine which institutions have better process performance as well as what drives this performance. Our use of this composite score as the measure of an institution's process performance indicates that we view an institution as a collection of processes. Our collected data on a representative sample of these processes leads us to assume that the performance of this sample is representative of the performance of the institution as a whole. We are now in a position to compare one institution with another based on relative process performance. The eigenvector that is produced in the final step of the above algorithm is a cardinal rank of process efficiency by institution. The eigenvector is then used as the basis for determining the ordinal rank of each institution

\section{Application to Financial Services}

In order to illustrate the process ranking methodology described above, consider the case of analyzing the relative efficiency of banks. Why banks and why process data? To begin with, financial services comprise over 4\% of the Gross Domestic Product in the United States as well as employing over 5.4 million people, more than double the combined number of people employed in the manufacture of apparel, automobiles, computers, pharmaceuticals, and steel ${ }^{2}$. Given the size and importance of this sector, it is a surprise to see very few rigorous studies of process management in this industry. In general, a large number of econometric studies have been undertaken over the past decade dealing with the efficiency of banks. The typical study attempts to ascertain whether scale or scope economies exist in banking. In addition to these traditional economic explanations of performance differences among firms, recent studies have focused on the notion of $X$-efficiency, a measure of the performance of an organization relative to the best practice in that industry. More precisely, $\mathrm{X}$-efficiency describes all technical and allocative efficiencies of individual firms that are not scale/scope dependent. Thus $X$-efficiency is a measure of how well management is deploying technology, human resources, and other assets to achieve a given level of performance. As stated by Berger, Hunter, and Timme (1993):

The one result upon which there is virtual consensus is that $\mathrm{X}$-efficiency differences across banks are relatively large and dominate scale and scope efficiencies.

Based on this evidence, it is clear that scale and scope economies are not the driving factor in explaining firm-level efficiency. Rather, holding these effects constant, our focus is to explain why $\mathrm{X}$-efficiency varies among financial institutions. That is, our goal is to understand how process management methods vary across these organizations and how this variation affects performance. In so doing, we are attempting to address the concern raised by Berger, Hancock, and Humphrey (1993) at the conclusion of their profit efficiency study of banks:

2 Comparison based on average 1991 data reported by the U. S. Bureau of Labor Statistics, Employment and Eamings Report, March 1992. Data for the financial services industry includes SIC codes 60-64 and 67. Data for the apparel, automobile, computer, pharmaceutical and steel industries include SIC codes 239 (less 23), 371, 357, 283, 331, and 332. 
Our results suggest that inefficiencies in U. S. banking are quite large - the industry appears to lose about half of its potential variable profits to inefficiency. Not surprisingly, technical inefficiencies dominate allocative inefficiencies, suggesting that banks are not particularly poor at choosing input and output plans, but rather are poor at carrying out these plans.

Therefore, our focus is on the implementation of strategies rather than the strategies themselves. In particular, our goal in the research summarized herein is to ascertain how financial institutions are deploying advanced process management practices, and to measure the impact of these practices on the quality and efficiency of the service delivery processes of the financial institution.

The purpose herein is to understand the causes of inefficiency at the operating level within retail banking. Thus, the approach taken in this study involves the collection of operational process-level data across a sample of retail banks. Through the analysis of such 'micro-level' data, the goal is to explain drivers of $\mathrm{X}$ efficiency.

The collection of this data is part of the work undertaken by the retail banking study at the Wharton Financial Institutions Center. The retail banking study is an interdisciplinary research effort aimed at understanding the drivers of competitiveness in the industry, where competitiveness means not simply firm performance but the relationship between industry trends and the experiences of the retail banking labor force. In the exploratory first phase of a study of the American retail banking industry, a research team conducted open-ended and structured interviews with industry informants from summer 1993 through fall 1994 , and shared its impressions with these informants at a number of conferences. The broad agenda for the retail banking study entails furthering the understanding of competitiveness in the industry.

Data has been collected on eleven processes which represent the bulk of the work that occurs at a typical retail bank's branch. The goal of this data collection! in conjunction with the analytical tools described above, is to ascertain the drivers of performance in retail banking, as well as to understand the causes of Xefficiency. That is, we attempt to identify which human resource and information technology practices influence both good and bad process performance, and which seem to have no effect at all. It should be noted that although we understand that there are many other drivers of process performance (e.g., strategic direction), for the scope of this work we will just concentrate on human resources and information technology. These processes span five products and represent opening of accounts, error correction on the part of the bank, and error correction on the part of the consumer.

For each of the eleven processes described in Table 5, we have performed the efficiency analysis using the Frei and Harker (1996) methodology. This analysis determines the efficiency with which each bank produces a set of outputs from a set of inputs. The categories of inputs and outputs for each process are shown in Table 5. For each process, we have ranked the banks according to their efficiency score, and thus have up to eleven rankings for each of the banks. The complete list of rankings for the large and small banks can be found in Frei (1996).

Using the individual process results, the aggregation methodology described herein was used to create the institutional efficiency rankings (see Frei 1996, Appendix F, for details). Thus, we created an institutional efficiency measure based upon each institutions performance on up to eleven processes. Using these institutional efficiency measures, we next looked for correlation with these process efficiency scores and asset size in order to determine if scale was a factor. We found there to be no significant correlation between asset size and process performance as can be seen in Figure 4 (p-value of 0.1390 ) for large banks and in Figure 5 for small banks ( $p$-value of 0.5180 ). Note that the further a bank is from the frontier, the more inefficient that bank is and the larger it's process performance score. 
Table 5. Process Inputs and Outputs for the Banking Data Set

\begin{tabular}{|c|c|c|c|}
\hline Open Checking Account & $\begin{array}{l}\text { Activity Time } \\
\text { Checking IT Functionality }\end{array}$ & $\begin{array}{l}\text { Customer Time } \\
\text { Check Cycle time } \\
\text { ATM Cycle Time }\end{array}$ & \\
\hline Open $S B L$ & $\begin{array}{l}\text { Activity Time } \\
\text { SBL IT Functionality }\end{array}$ & $\begin{array}{l}\text { Customer Time } \\
\text { Approval Cycle time } \\
\text { Money Cycle Time }\end{array}$ & \\
\hline Open $C D$ & $\begin{array}{l}\text { Activity Time } \\
\text { CD IT Functionality }\end{array}$ & Customer Time & \\
\hline Open Mutual Fund & $\begin{array}{l}\text { Activity Time } \\
\text { MF IT Functionality }\end{array}$ & Customer Time & \\
\hline Open Home Equity & $\begin{array}{l}\text { Activity Time } \\
\text { HE IT Functionality }\end{array}$ & $\begin{array}{l}\text { Customer Time } \\
\text { Approval Cycle Time } \\
\text { Money Cycle Time }\end{array}$ & \\
\hline Correct Checking & $\begin{array}{l}\text { Activity Time } \\
\text { Checking IT Functionality }\end{array}$ & $\begin{array}{l}\text { Customer Time } \\
\text { Correct Cycle Time }\end{array}$ & \\
\hline Correct Home Equity & $\begin{array}{l}\text { Activity Time } \\
\text { HE IT Functionality }\end{array}$ & $\begin{array}{l}\text { Customer Time } \\
\text { Post Cycle Time } \\
\text { Notify Cycle Time }\end{array}$ & \\
\hline Correct Small Business & $\begin{array}{l}\text { Activity Time } \\
\text { SBL IT Functionality }\end{array}$ & $\begin{array}{l}\text { Customer Time } \\
\text { Post Cycle Time } \\
\text { Notify Cycle Time }\end{array}$ & $\because$ \\
\hline Redeem Premature $C D$ & $\begin{array}{l}\text { Activity Time } \\
\text { CD IT Functionality }\end{array}$ & $\begin{array}{l}\text { Customer Time } \\
\text { Redeem Cycle-Time }\end{array}$ & \\
\hline Stop Payment & $\begin{array}{l}\text { Activity Time } \\
\text { Checking IT Functionality }\end{array}$ & Customer Time & \\
\hline Replace Lost ATM & $\begin{array}{l}\text { Activity Time } \\
\text { Checking Tech Functionality }\end{array}$ & $\begin{array}{l}\text { Customer Time } \\
\text { Replace Cycle Time }\end{array}$ & \\
\hline
\end{tabular}



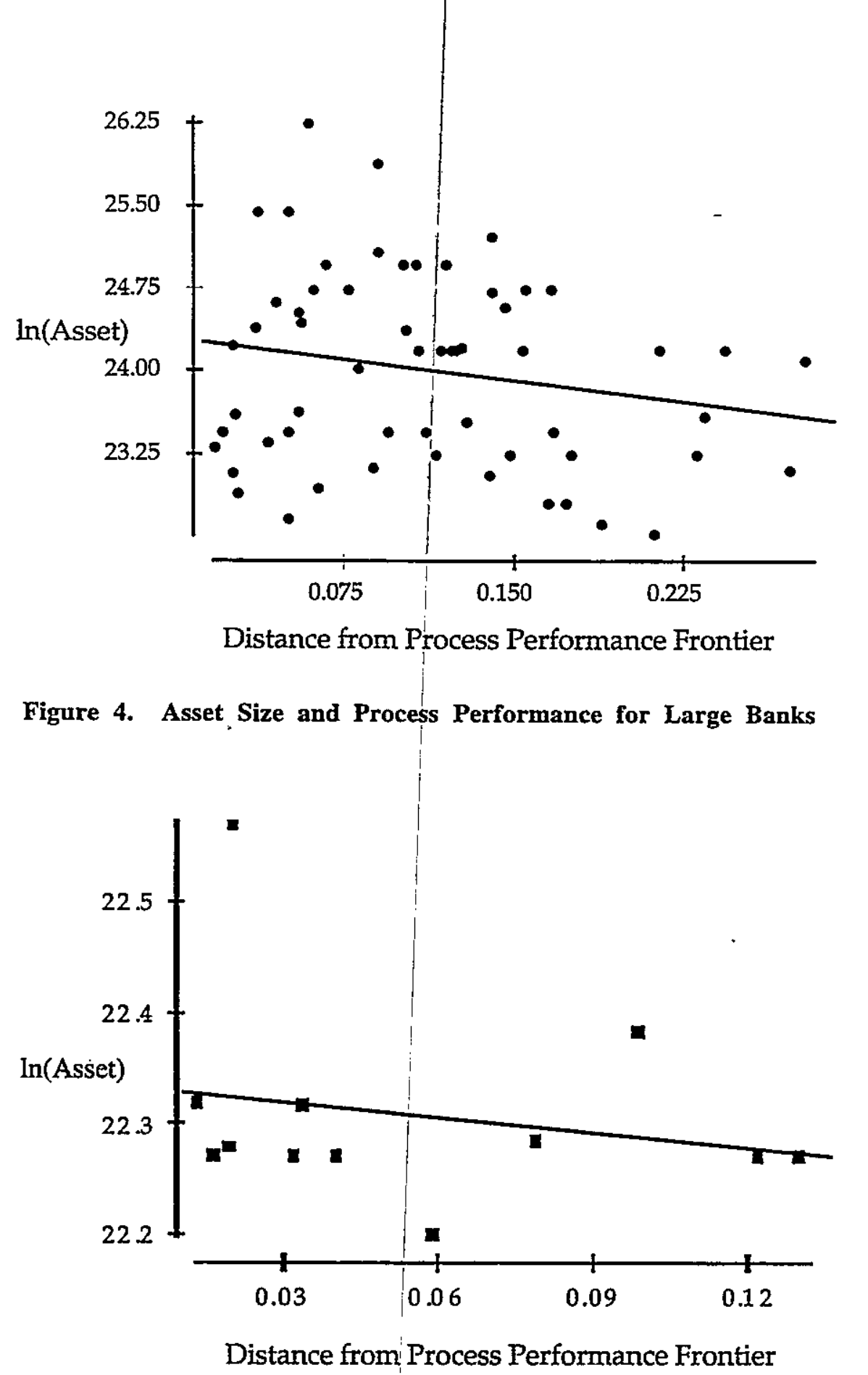

\section{Figure 5. Asset Size and Process Performance for Small Banks}

In addition, we explored the relationship of process efficiency with number of employees, net interest expense, net interest income, fee income, and stock price, and similarly found no significant relationship. These results support the previous econometric work by Berger, Hancock, and Humphrey (1993) which showed that it is neither scale nor scope but rather management practices, or X-efficiency, that drive performance. That is, from our approach we found no relationship between scale or scope and performance and similarly the econometric work of Berger et al. found no relationship.

Frei (1996) then used the results of the ranking methodology described herein to explore the drivers of process performance. Because the process serves as the site of the primary interaction of human resources and technology, these two areas of management practices were studies in order to determine if they drive process performance.

Figure 6 shows a summary of our main findings which can be summarized as follows: 
1. There is a negative relationship between process performance and information technology (TT) investment for large banks. This result is opposite of our initial hypothesis as we expected that the more money an institution spent on IT the better their process performance. However, if we group the banks according to their IT functionality we find that there is a positive relationship between process performance and IT investment for the high functionality banks. Thus, technology only seems to "pay off" when a significant commitment is made to creating high-functionality systems.

2. There is a negative relationship between process performance and advanced human resource management practices for large banks. These management practices, typically referred to as High Performance Workplace (HPWP) systems, as compared to high-control work environments, are characterized by a high-commitment, high-involvement workplace (Huselid 1995; MacDuffie 1995). A comparison of the high-performance workplace and high-control workplace is shown in Table 6 which is reproduced from Hunter (1995). This result is opposite of our hypothesis as we expected that the more empowered the workforce, the better the process performance. However, if we group the banks according to their IT investments, there is a positive relationship between process performance and HPWP for those banks making large IT investments.

3. Extending the second finding, we found that banks that had low IT investments and less evidence of the HPWP (basically routine banking operations with few "frills" in the operation), performed well on processes. Thus, a bank can achieve efficiency by nuning a "McDonald's-like" production operation and providing a low-cost banking service, or by making substantial investments in people and technology to create high-quality banking. It is the middle ground that arises from the convex combination of the two strategies that causes inefficiency in the industry (see Figure 6 for a summary of this relationship).

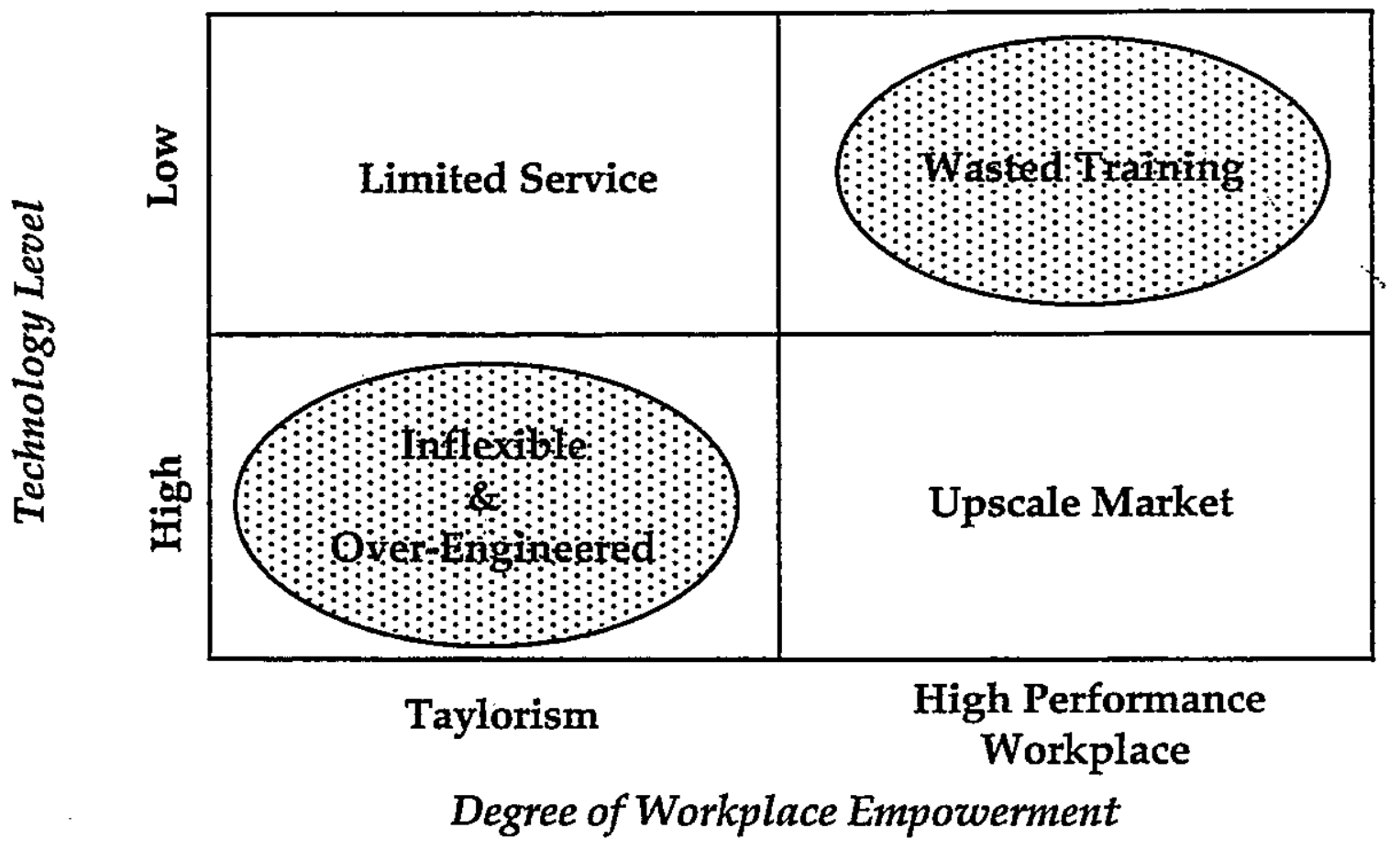

Figure 6. Summary of Findings 
Table 6. Components of the High Performance Work Place (HPWP)

\begin{tabular}{llll} 
& High-Control & High-Performance Practice \\
Workplace & Workplace \\
\hline Compensation & Low base pay & High base pay \\
& Individual incentives & Group incentives \\
& Few rewards for tenure & Back-loaded pay \\
& High differentials across jobs & Lower differentials \\
\hline Training & Low levels & High levels \\
\hline Staffing & Extensive low-cost, p/t workforce & Full-time workforce \\
& Hire and fire at will & Employment security \\
\hline Hiring \& Selection & Staff for immediate needs & Looser staffing \\
\hline Workplace Governance & Based on the market & High investment in screening \\
\hline Lob Design & Little employee involvement & Extensive employee involvement \\
& Relatively narrow jobs & Broader jobs \\
& Steep hierarchy & Flat hierarchy \\
& Emphasis on monitoring & \\
\hline
\end{tabular}

This paper has presented a new methodology for determining a composite measure for institutional process performance given business process-level data. The tournament ranking literature has been extended to allow for the situation in which one competitor wins all of the matches between two competitors. This extension was necessary as we searched for a way to determine a composite process performance score for each institution in our sample when we had between one and eleven process scores for each. Such an approach is clearly needed for any type of process-level analysis of efficiency. The application to the U.S. retail banking industry illustrates the power that such a methodology brings to the analysis of the drivers of competitiveness.

The proposed methodology treats all processes as equivalent when undertaking the aggregation procedure. Obviously, some processes matter more to an organization or an industry than others. Thus, a clear extension of the current methodology is to weight the various process performance metrics by their importance, and to then conduct the synthesis to generate the institutional rankings; this is left for future research.

\section{References}

Berger, A. N., Hancock, D., Humphrey, D. B. (1993), "Bank Efficiency Derived from the Profit Function," Journal of Banking and Finance, 17, 317-348.

Berger, A. N. and Humphrey, D. B. (1992), "Measurement and efficiency issues in commercial banking," in Z. Griliches (ed.), Output Measurement in the Services Sector: National Bureau of Economic Research Studies in Income and Wealth, Chicago: University of Chicago Press. 
Berger, A. N., Hunter, W. C., and Timme, J. (1993), "The Efficiency of Financial Institutions: A Review and Preview of Research Past, Present and Future," Joumal of Banking and Finance, 17, 221-250.

Brockett, P. L. and B. Golany (1994), "Using Rank Statistics for Determining Programmatic Efficiency Differences in Data Envelopment Analysis," Management Science, forthcoming.

Davenport, T. H. and Short J. E. (1990), "The New Industrial Engineering: Information Technology and Business Process Redesign," Sloan Management Review, 31, 11-27.

Frei, F. X. and Harker, P. T. (1995), "Projections Onto Efficient Frontiers: Theoretical and Computational Extensions to DEA," Working Paper, Wharton Financial Institutions Center, The Wharton School, University of Pennsylvania, Philadelphia, PA.

Frei, F. X. and Harker, P. T. (1996), "Process design and Efficiency: Evidence From Retail Banking," Working Paper, Wharton Financial Institutions Center, The Wharton School, University of Pennsylvania, Philadelphia, PA.

Frei, F. X. (1996), "The Role of Process Designs in Efficiency Analysis: An Empirical Investigation of the Retail Banking," Unpublished Dissertation, The Wharton School, University of Pennsylvania, Philadelphia, PA.

Hammer, M. and Champy J. (1993). Reengineering the Corporation: A Manifesto for Business Revolution, New York: HarperBusiness.

Harker, P. T. (1987), "Alternative Modes of Questioning in the Analytic Hierarchy Process," Mathematical Modeling, 9, 353-360.

Harker, P. T. and Vargas V. G. (1987), "The Theory of Ratio Scale Estimation: Saaty's Analytic Hierarchy Process," Management Science, 33, 1383-1403.

Hunter, L. W. (1995), "Human Resource Practices in Retail Banking," Working Paper, Wharton Financial Institutions Center, The Wharton School, University of Pennsylvania, Philadelphia, PA.

Huselid, M. A. (1995), "The Impact of Human Resource Management Practices on Turnover, Productivity, and Corporate Financial Performance," Academy of Management Joumal, 38, 635-672.

Kingman-Brundage, J. (1992), "The ABCs of Service System Blueprinting," in C.H. Lovelock (ed.), Measuring Services, Second Edition, Englewood Cliffs: Prentice Hall.

MacDuffie, J. P. (1995), "Human Resource Bundles and Manufacturing Performance: Organizational Logic and Flexible Production Systems in the World Auto Industry," Industrial and Labor Relations Review (January).

Morroni, M. (1992). Production Processes and Technical Change, London: Cambridge University Press.

Saaty, T. (1986), "Axiomatic Foundation of the Analytic Hierarchy Process," Management Science, 32, 841-855.

Shostack, G. L. (1987), "Service Positioning Through Structural Change," Journal of Marketing, 51, 3443. 